\title{
Percepções de Alunos de Graduação sobre Gênero em Ciência da Computação
}

\author{
Uyara F. Silva $^{12}$, Deller J. Ferreira ${ }^{1}$, Ana Paula L. Ambrósio ${ }^{1}$, João L. S. Oliveira ${ }^{1}$ \\ ${ }^{1}$ Instituto de Informática - Universidade Federal de Goias (UFG) \\ Caixa Postal 131 - 74001-970 - Goiânia- GO - Brasil \\ ${ }^{2}$ Instituto Federal de Educação, Ciência e Tecnologia de Goiás \\ Parque Lago - 73813-816 - Formosa - GO - Brasil \\ uyara.silva@ifg.edu.br, dellereufg.br \\ \{apaula, joaosantos\}@inf.ufg.br
}

\begin{abstract}
Higher education environments in the area of computing have several problems faced by female students. In this article, students' perceptions of these problems were investigated, where data and reports were collected on unpleasant facts that happened to the students. An online questionnaire was answered by 300 undergraduate students in computer courses from 23 institutions in Brazil. The collected data were analyzed using statistical and qualitative methods. The results show that the majority of students of both sexes have a low sense of belonging and also that men carry part of the problems. However, girls sufferers more with discrimination and gender stereotype than boys.
\end{abstract}

Resumo. Ambientes de cursos superiores, na área de computação, possuem vários problemas enfrentados por estudantes do sexo feminino. Neste artigo foram investigadas as percepções dos alunos sobre estes problemas, onde foram coletados relatos sobre fatos desagradáveis que aconteceram com os alunos assim como outros dados. Um questionário online foi respondido por 300 estudantes de graduação de cursos de computação de 23 instituições do Brasil. Os dados coletados foram analisados por métodos estatísticos e qualitativos. Os resultados mostram que a maioria dos estudantes de ambos os sexos têm um baixo sentimento de pertencimento e também que os homens carregam parte dos problemas. No entanto, as meninas sofrem mais com discriminação e estereótipo de gênero que os meninos.

\section{Introdução}

Meninas que cursam Ciência da Computação percebem que são duplamente isoladas, tanto dentro como fora da área [Cheryan et al. 2019]. Muitos estudos comportamentais revelaram que o clima social dos campi, com cursos de computação, afeta a participação e o sucesso das meninas [Cheryan et al. 2009, Leslie et al. 2015, Ceci 2015, Moss-Racusin et al. 2018]. Este ambiente inóspito proveniente dos cursos de computação é devido a alguns fatores como a desvalorização de gênero, estereótipo e até mesmo assédio [Misa 2011], tudo isto afeta o auto confiança das meninas e proporciona o baixo sentimento de pertencimento das mesmas [Strayhorn 2018]. 
Devido a discriminação de gênero, as meninas interessadas nas carreiras de computação enfrentam dificuldades na entrada e permanência na universidade. De acordo com o jornal da Universidade de São Paulo (USP), nos últimos cinco anos, apenas 9\% dos alunos do curso de Ciência da Computação do Instituto de Ciências Matemáticas e da Computação (ICMC) da USP, em São Carlos, eram do sexo feminino; no Bacharelado em Sistemas de Informação, $10 \%$ e; Engenharia de Computação, 6\% [Santos 2018]. Os cursos da área de computação (Análise e Desenvolvimento de Sistemas, Ciências da Computação, Gestão da Tecnologia da Computação, Informática, Redes de Telecomunicações e Sistemas para a Internet) oferecidos pelos Institutos Federais de Ciência e Tecnologia do Estado de Goiás possuem 1058 matrículas no ano de 2018, sendo que apenas 193 são do sexo feminino [DTI-MEC 2018].

Para um melhor entendimento deste cenário, a presente pesquisa coletou dados de estudantes de cursos superiores de computação em 23 instituições de ensino do Brasil através de um questionário online. As questões foram desenvolvidas de acordo com os problemas apontados por diversas bibliografias com o intuito de reafirmar a existência destes problemas e explanar sobre as diferenças de gênero neste contexto. Foram realizadas análises estatísticas e qualitativas para esclarecer e fornecer informações sobre as perspectivas dos alunos em relação ao ambiente acadêmico. A compreensão desse cenário é muito importante para que os professores e demais profissionais nas universidades tenham subsídios para realizar mudanças dentro da sala de aula e adquirir conhecimentos que possam auxiliar em ações adicionais visando o bem-estar dos alunos e permanência nos cursos.

Os resultados deste estudo apontam quais problemas afetam mais as meninas no contexto das universidades do Brasil, e se estes problemas afetam mais elas que os meninos. Este estudo verificou também quais as diferenças percebidas nas percepções de ambos em relação ao ambiente universitário de computação.

\section{Trabalhos Relacionados}

Tem havido um crescente interesse em pesquisas acadêmicas relacionadas a problemas de gênero. No âmbito universitário, [Michell et al. 2017] discorrem sobre o assédio sexual fazendo alusão à análise filosófica das "cinco faces"da opressão, para sugerir estratégias pelas quais as universidades australianas poderiam apoiar as mulheres na ciência da computação e educar os homens sobre comportamento respeitoso e igualdade de gênero.

Além do assédio sexual, mulheres na computação enfrentam problemas como humilhação, objetivação e preconceito. Vários artigos apontam o estereótipo de gênero como sendo um dos maiores problemas enfrentados pelas meninas que frequentam cursos superiores de computação [Giannakos et al. 2017, Casad et al. 2019], sendo que o estereótipo negativo pode diminuir o sentimento de pertencimento das meninas [Master et al. 2016].

Pesquisas abordando cursos superiores de computação também endereçam diferenças e similaridades entre os sexos, desvendando, por exemplo, uma grande distinção entre a autoconfiança de meninos e meninas na área de computação. Além dos meninos relatarem acreditar mais que as meninas em sua capacidade, na prática, eles também são muito mais propensos a receber apoio e incentivo de pais e amigos. Porém meninos e meninas, geralmente têm a mesma capacidade, porém a autoconfiança é ne- 
cessária para a motivação e permanência das meninas nas universidades [Mishkin 2019].

Apesar de existirem pesquisas internacionais relatando problemas das mulheres em cursos de computação, há uma demanda de pesquisas similares no Brasil. No Brasil, sabemos que o número de meninas que entram e concluem cursos de computação em nível superior é bem inferior a dos meninos, contudo pouco se sabe dos possíveis motivos da evasão das meninas nesses cursos e os problemas por elas sofridos.

\section{Metodologia}

Nesta pesquisa foi realizado um estudo de caso seguindo o processo de [Yin 2015]. Foi divulgado um questionário online em 23 instituições de nível superior que possuem cursos na área de Ciências da Computação no segundo semestre de 2019, estas instituições contemplam diversos estados do Brasil. O questionário foi divulgado com ajuda do grupo de e-mails das Meninas Digitais da SBC (Sociedade Brasileira de Computação) e docentes de universidades brasileiras.

O questionário foi respondido por 300 estudantes de nível superior da área de Ciências da Computação. Com o intuito de selecionar maior número de meninas, ele foi divulgado somente para elas cerca de 15 dias antes de ser liberado para todos os alunos deste eixo. O questionário solicitou informações básicas sobre os participantes: sexo, idade, instituição de ensino, curso, período do curso e escolaridade dos pais. Essas informações foram usadas no processo de seleção de participantes para obter diversidade e para triangular as fontes de dados durante a análise dos dados. Dados pessoais como nome e matrícula permanecem confidenciais para a integridade dos estudantes e para evitar constrangimentos.

O intuito do questionário foi mapear os principais problemas sofridos por meninas que estudam Ciências da Computação, mencionados em várias bibliografias, como o estereótipo de gênero, o isolamento das meninas, baixa auto confiança e baixo sentimento de pertencimento.

O questionário continha 25 perguntas, sendo 13 perguntas sobre as percepções dos alunos em relação ao ambiente universitário e 7 perguntas sobre fatos negativos que ocorreram a eles. Para entender, além das percepções coletivas, as experiências individuais dos participantes e como eles pensavam, 5 perguntas possuíram respostas abertas e opcionais.

As 20 primeiras perguntas possuíam opções de respostas que seguem a escala Likert. Para as respostas das questões sobre percepções, a escala Likert seguiu o padrão: $1=$ nada; $2=$ pouco; $3=$ neutro; $4=$ razoavelmente e; $5=$ muito. Para as respostas das perguntas sobre fatos, a escala Likert seguiu o padrão: $1=$ nunca; $2=$ uma vez; $3=$ duas ou três vezes; $4=$ quatro vezes e; $5=$ mais de quatro vezes. As perguntas que seguiram a escala Likert são descritas abaixo:

1. Quanto você acha que as pessoas do seu gênero são valorizadas pelos outros atuando em computação?

2. Quanto você acha que seu gênero influenciará na conquista de um bom emprego na área de computação?

3. Quanto você acha que é discriminado(a) por estudar computação?

4. Quanto o estereótipo negativo a respeito dos profissionais, do seu gênero, na computação o(a) incomoda? 
IX Congresso Brasileiro de Informática na Educação (CBIE 2020)

Anais do XXXI Simpósio Brasileiro de Informática na Educação (SBIE 2020)

5. Quanto você se preocupa com o fato de as pessoas tirarem conclusões sobre o seu desempenho com base no seu gênero?

6. Quão bem você acha que se sairia trabalhando com computação?

7. Quão bem você acha que se sai como estudante de computação?

8. O quanto você se acha similar aos seus colegas que também estudam computação?

9. Qual a sua proximidade com as pessoas do seu curso?

10. Quanto você acha que se encaixaria no ambiente de trabalho, na área de computação?

11. Você se preocupa em ser rotulado(a) negativamente por estudar computação?

12. Quais são as chances de você NÃO concluir o curso superior na área de computação?

13. Quais são as chances de você NÃO seguir carreira na área de computação?

14. Seus colegas ou professores já o(a) provocaram (negativamente) por estudar computação? Exemplo: o(a) deram apelidos pejorativos.

15. Seus colegas ou professores já o(a) interromperam enquanto você falava, não permitindo que você concluísse seu raciocínio?

16. Alguma vez seus colegas ou professores insinuaram que você estava perdendo a razão ao dar alguma opinião diversa da deles?

17. Alguma vez seus colegas o(a) subestimaram? Por exemplo, explicaram algo óbvio com alguma entonação que o(a) incomodou.

18. Alguma vez seus colegas apropriaram de uma ideia sua como se fossem deles e levaram o crédito por isso?

19. Alguma vez foi assediado(a) dentro da instituição de ensino?

20. Alguém na instituição fez piadas, insinuações ou o(a) constrangeu de alguma outra forma?

Para as perguntas de 1 a 20 foram calculadas a medianas das respostas de toda a amostra, respostas das meninas e por fim calculada a mediana das respostas dos meninos, desta forma foi verificado se havia desproporção nas percepções sentidas por meninos e meninas. Também foram feitos testes inferenciais de diferença utilizando Mann-Whitney, este teste foi escolhido porque a variável dependente é ordinal e as variáveis independentes são os grupos meninas e meninos. A hipótese nula é representada por $H_{0}$ (o resultado encontrado é devido ao acaso) e a hipótese alternativa é representada por $H_{1}$ (o resultado encontrado não é devido ao acaso). A variável $p$ representa a probabilidade de diferença, é uma probabilidade que mede a evidência contra a hipótese nula. Se $p>0,05$, o resultado é não significativo, caso contrário, o resultado é significativo.

As últimas 5 perguntas serviram para análise qualitativa individual de cada aluno. Estas perguntas estão descritas abaixo:

21. Apenas se sentir a vontade, escreva sobre suas interações no curso de computação ou relate algum fato em que se sentiu isolado(a).

22. Apenas se sentir a vontade, escreva sobre seus receios ou relate algum fato em que se sentiu com a confiança baixa em computação.

23. Apenas se sentir a vontade, escreva como os rótulos o(a) afetam ou relate algum fato ocorrido com você ou outro(a) estudante próximo(a) a você que cursa computação relativo a este problema.

24. Por que escolheu o curso de computação?

25. Qual das palavras abaixo descreve melhor sua experiência no curso superior de computação? 


\section{Resultados e Discussão}

Foram obtidas 300 respostas de estudantes de computação por todo o Brasil, $58 \%$ se declararam do sexo masculino, $41 \%$ se declararam do sexo feminino e $1 \%$ se declararam pertencentes a outro gênero. As idades variaram entre 18 e 33 anos, salva algumas poucas exceções. $27 \%$ dos alunos informaram que o curso de computação não foi a primeira opção. Sobre a escolaridade das mães, 18, 7\% possuem educação básica, 35, $7 \%$ possuem segundo grau, $44,3 \%$ possuem nível superior e $1,3 \%$ dos estudantes não souberam informar. Sobre a escolaridade dos pais, $26 \%$ possuem educação básica, $31,3 \%$ possuem segundo grau, $33,7 \%$ possuem nível superior e $9 \%$ dos alunos não souberam informar o grau de escolaridade dos pais. É possível notar que o número de estudantes que desconhecem o nível de escolaridade da mãe é bem menor que o número que desconhecem o nível de escolaridade do pai. Outra informação relevante é que o número de mães com nível superior é maior que o número de pais com nível superior.

\subsection{Análise Estatística}

Vale ressaltar que as análises feitas para este trabalho desconsideraram os estudantes que selecionaram a opção outros para informar o sexo, pois este cenário precisa de estudos mais profundos e não é o foco deste artigo. A desproporção mais significativa entre as percepções de mulheres e homens é mais perceptível nas respostas das perguntas 1, 3, 4, 5 e 11. A Figuras 1 mostra os gráficos de barras com os números de estudantes de cada sexo e os itens escolhidos por eles da escala Likert.

A mediana das respostas da questão 1 é 4 para todos os alunos, 2 para as meninas e 5 para os meninos. Diferença de 3 pontos entre meninas e meninos. As respostas da pergunta 3 possui mediana 2 para toda a amostra, 3 para as meninas e 1 para os meninos. Diferença de 2 pontos entre meninas e meninos. As respostas da pergunta 4 possuem mediana 3 para todos os alunos, 4 para as meninas e 2 para os meninos. Diferença de 2 pontos entre meninas e meninos. As respostas da pergunta 5 possuem mediana 3 para todos os alunos, 5 para as meninas e 2 para os meninos. Diferença de 3 pontos entre meninas e meninos. A Figura 1 mostra os gráficos de barras das respostas das perguntas $Q_{1}, Q_{3}, Q_{4}$ e $Q_{5}$.

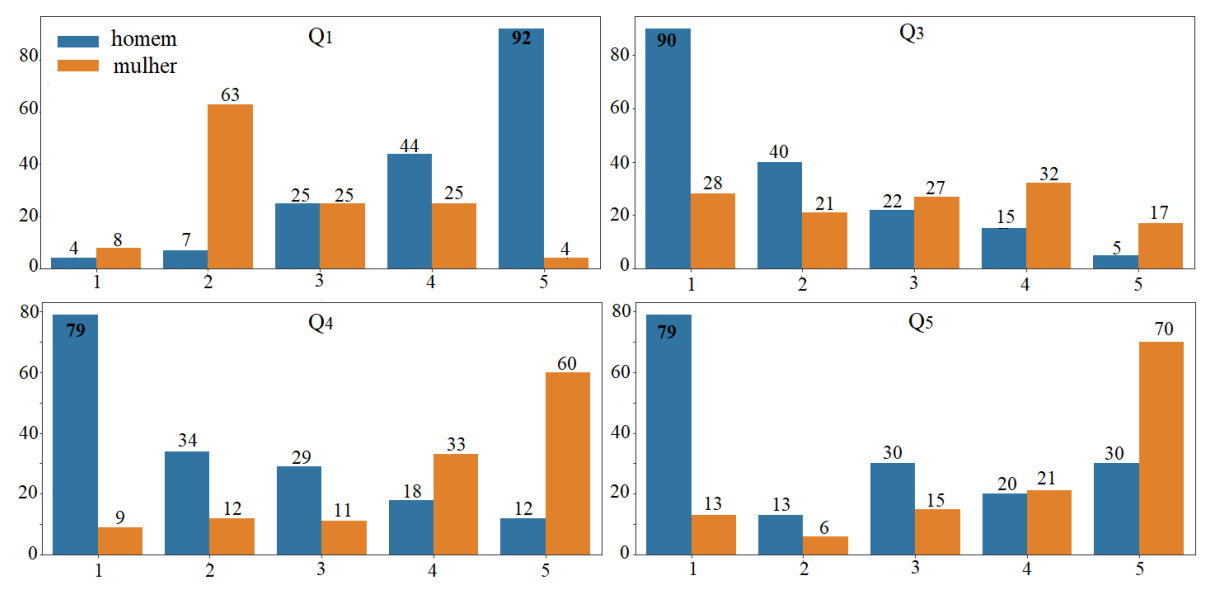

Figura 1. Respostas das perguntas $Q_{1}, Q_{3}, Q_{4}$ e $Q_{5}$. 
O resultado das respostas da pergunta 1 indica o quanto a desvalorização de gênero incomoda as estudantes mesmo antes de graduarem e enfrentarem o mercado de trabalho por si mesmas. Isso se deve, muito provavelmente, por falta de referências femininas nas áreas da computação (seja pelo quadro de docentes ínfimo de mulheres e falta de referência na própria família) e também pelos relatos e estudos que indicam a diferença salarial entre homens e mulheres no mercado tecnológico competitivo.

A pergunta 3 se refere a discriminação percebida, como relatado em outras bibliografias a falta de credibilidade, situações de humilhação, objetificação e preconceito perpetuam diariamente na vida das meninas que lutam por um espaço na Ciência da Computação. Manterrupting, gaslighting, mansplaining e bropriating são exemplos de discriminação na qual as estudantes estão sujeitas.

As respostas da pergunta 4 indicam que as meninas se preocupam muito mais com a ameaça do esteriótipo de gênero do que os meninos. Na época do filme "Vingança dos Nerds", década de 1980 tanto homens e mulheres da área de computação tinham o estereótipo de serem anti-sociais, de aparência desagradável e comportamentos estranhos. Este estereótipo dos homens não está mais tão negativo, hoje homens que seguem carreiras de computação são imaginados pela maioria como sendo bem sucedidos e com inteligência acima da média, o mesmo não aconteceu com o estereótipo em relação às mulheres, que permanece degradante.

A pergunta 5 também está relacionada com a desvalorização de gênero, assim como as perguntas 1 e 2 . As respostas da pergunta 11 possui mediana 1 para todos os alunos, 2 para as meninas e 1 para os meninos. Diferença de 1 ponto entre meninas e meninos. Apesar da diferença numérica ser pequena, as respostas mostram que as meninas se preocupam mais que os meninos em serem rotuladas negativamente.

A desproporção mais significativa entre os fatos ocorridos com mulheres e homens é mais perceptível nas respostas das perguntas 15, 17 e 20. As respostas da pergunta 15 possui mediana 2 para todos os alunos, 3 para as respostas das meninas e 2 para os meninos. As respostas da pergunta 17 possui mediana 3 para todos os alunos, 3 para as respostas das meninas e 2 para as respostas dos meninos. Já a pergunta 20, possui mediana 2 para as respostas de todos os alunos, 2 para meninas e 1 para meninos. As respostas destas perguntas tiveram diferença de 1 ponto entre meninas e meninos. Mesmo que a diferença quantitativa das respostas seja baixa para estas últimas respostas, não se pode inferir que a diferença qualitativa entre os fatos ocorridos com meninas e meninos seja insignificante.

Vários testes de diferenças foram feitos considerando várias questões, o que mais teve significância foi o que a pergunta de investigação era: 'Existe uma diferença significativa entre meninas e meninos quanto a pretensão de seguir carreia de computação?' A hipótese alternativa foi aceita, ou seja, existe diferença significativa entre os dois grupos, como era de se esperar, a pretensão em seguir carreira de computação dos meninos é bem maior que das menias, $p=0,0056$.

\subsection{Análise Qualitativa}

Na pergunta 24 muitos alunos informaram que escolheram o curso por gostarem e terem afinidade com a área de informática e outros justificaram a escolha do curso por ter uma ótima empregabilidade. Alguns informaram que escolheram o curso por falta de opção 
ou como segunda opção. Outros ainda, relataram que outras pessoas, normalmente da família, os induziram a escolherem o curso. Vários optaram por curiosidade. Mais de um estudante informou que escolheu o curso por ser mais próximo de casa.

A pergunta 25 que pede para o aluno resumir a experiência deles no curso superior de computação, em uma só palavra, apesar de possuir resposta aberta, indicava algumas alternativas como: desafiante, estressante, enriquecedora, solitária e prazerosa. $43,7 \%$ dos alunos escolheram a opção desafiante; $20 \%$ escolheram a opção estressante; $14,3 \%$ escolheram a opção enriquecedora; $8,3 \%$ escolheram a opção solitária e; $7,3 \%$ escolheram a opção prazerosa. Tiveram poucas respostas de escolha livre, mas um fato que chamou a atenção é que alguns alunos escreveram desencorajadora e outros sinônimos em suas respostas. Mais de um aluno também mencionou a palavra depressiva. Alguns alunos apontaram a falta de didática dos professores e disciplinas muito difíceis como causa destas frustrações.

Para o estudo das respostas das perguntas 21, 22 e 23 foram separadas as respostas das meninas dos meninos e foram feitas triangulações destas respostas para encontrar padrões.

Isolamento. Sobre o isolamento tratado na pergunta 21, os meninos não demonstraram pertubações relativas a serem isolados pelo fato de serem meninos, porém, todas as meninas que apontaram o isolamento como um problema o justificaram pelo fato de serem meninas.

Me sinto isolada diversas vezes, porque o curso é majoritariamente masculino e, para evitar qualquer tipo de assédio ou desconforto, evito interação, isso faz com que eu tenha poucos conhecidos no curso.

Menina de 20 anos

Analisando as respostas é perceptível a alienação de alguns estudantes meninos em relação às vivências e experiências negativas sofridas pelas meninas no ambiente educacional. Um estudante chegou a afirmar que para elas conseguirem notas boas é ainda mais fácil, pois todos as ajudam por serem meninas. Outro menino indicou o isolamento como sendo um traço comum da pessoas que são da área de tecnologia.

Baixa Autoconfiança. As respostas para a pergunta 22 podem ser sintetizadas em mercado de trabalho, dificuldade com desenvolvimento, competitividade entre colegas e falta de didática e suporte por falta dos professores.

Os alunos, de ambos os sexos, se mostraram muito preocupados com o mercado de trabalho, por ser muito competitivo, exigente e injusto. Relataram que muitas vezes as empresas cobram experiências que não são de iniciantes e oferecem salários muito irrisórios. As meninas ainda têm preocupações a mais, devido a relatos de assédio e de salários menores.

Temo pelo mercado de trabalho, pois infelizmente a informática ainda é vista como uma área majoritariamente masculina, fazendo com que muitos esteriótipos, com relação a atuação da mulher no campo da informática, existam.

Uma estudante de 24 anos

Um ponto muito levantado por diversos estudantes, incluindo meninas e meninos, foi a falta de didática e motivação dos professores, que muitas vezes consideram que o 
aluno conhece conceitos que eles nunca tiveram contato, ou mesmo possuem habilidades nas quais nunca tiveram oportunidade de desenvolver. Também foi muito levantada a falta de suporte dos professores com aqueles que têm maior dificuldade, cobrança exacerbada, muitos inclusive citaram professores que demonstravam serem arrogantes e sem paciência, optando por dar aulas apenas para um grupo seleto de estudantes, estudantes estes que vieram de cursos técnicos ou/e outros que já trabalham na área de computação. As meninas novamente, declararam em suas respostas o grande problema em ser do sexo feminino, descrevendo discriminações de gênero por parte de professores e colegas.

A forma como parte dos professores ministram as aulas já me fizeram sentir intimidada e "burra". Partem da ideia própria de que temos um raciocínio lógico rápido e aguçado e que dominamos quase toda a matemática e explicam a matéria com tom de desprezo pra quem não estiver entendendo. Ainda me sinto muito pouco confiante com meu curso por não sentir apoio dos professores. Por me sentir incapaz de entender ou aprender. Tenho consciência de que é um curso difícil mas esperava mais suporte. Penso seriamente em transferir por não me sentir a vontade dentro do curso.

Uma estudante de 18 anos

A fala abaixo é um exemplo de mansplaining, quando o homem explica o óbvio para uma mulher. Muitas vezes quando a menina possui alguma dúvida técnica e pede ajuda para algum professor ou colega, este pode vir a começar a explicar o óbvio para a mesma, fugindo do que foi perguntado.

Querendo ou não, alguns colegas e professores te julgam diferente dos homens. Isso teve seus momentos bons e ruins. Algumas vezes explicavam coisas como se eu não entendesse nada do curso e outras vezes era beneficiada por ser mulher.

Uma estudante de 23 anos

O relato a seguir é só um de vários que demonstram o sentimento de pertencimento muito baixo e até mesmo mal estar no ambiente acadêmico.

Pelo fato de ser mulher, ter desistido do curso de enfermagem e não ter a mínima experiência na área, já aconteceu de professor chegar comigo e dizer que eu devia voltar pra enfermagem, que eu não levava muito jeito pra área de computação, e pra quando eu me formar cuidar dele como enfermeira. Isso me desanimou MUITO em continuar. Fiquei empurrando com a barriga por anos. Lógico que não só por esse motivo, mas foi algo que me marcou.

Acabei, depois de 4 anos, trocando de Ciência da computação pra Engenharia de Software, porque o ambiente de computação me fazia muito mal. Apesar de serem quase os mesmos professores, o ambiente era/é menos carregado pra $\operatorname{mim}$.

Uma estudante de 29 anos

Além destes problemas encontrados evidencia-se um considerável número de estudantes com dificuldades em desenvolvimento. Estes mesmos alunos demonstraram certo desconforto na competitividade gerada entre os colegas. Muitas vezes se sentem inferiores pois na sala de aula há os alunos com conhecimentos muito mais avançados que os deles (seja por vierem de cursos técnicos, já atuarem na área ou terem referências 
IX Congresso Brasileiro de Informática na Educação (CBIE 2020)

Anais do XXXI Simpósio Brasileiro de Informática na Educação (SBIE 2020)

na família), o que volta a questão do professor de não saber lidar com isso e começar a lecionar para um grupo seleto de estudantes.

Estereótipo. Nas respostas da pergunta 23 é confirmado o estereótipo de gênero em diversos relatos, seguem alguns deles:

Os rótulos prejudicam duas colegas minhas que estudam comigo, pois elas são muito mais inteligentes e capaz que eu mas rotulam elas como não capaz por ser mulher e me rotulam como capaz por ser homem. Quando demonstro que tenho dúvidas e peço ajuda a elas eu percebo surpresa no olhar das pessoas.

Piadas machistas e sexistas por parte dos alunos contra as professoras e outras alunas. Os alunos do curso tendem a elogiar os professores mais críticos e pulsos firmes, já as professoras são tratadas como loucas. O mesmo valor para as alunas, que são ofendidas por estas circunstâncias.

Algumas outras respostas reafirmam a alienação de alguns estudantes perante os problemas sofridos pelas meninas e até mesmo, pelas professoras.

Não tem essas coisas exageradas não. Todo mundo é de boa, sem vitimismo quando há brincadeiras.

\section{Conclusão}

Várias bibliografias relatam problemas sofridos por meninas estudantes de cursos da área de ciências da computação. Para esta pesquisa foram coletadas informações sobre as percepções dos alunos a respeito destes problemas, assim como relatos de fatos desagradáveis que ocorreram no âmbito da instituição educacional. Pôde-se perceber que os problemas sofridos pelas meninas apontados nas bibliografias são reafirmados nas respostas, mas não somente, os meninos também relataram medos e insegurança. É possível notar pelas respostas da pergunta 25 que vários estudantes entraram no curso com a expectativa de que o mercado de trabalho os beneficiariam com bons salários e proporcionaria um certo status. Porém, pelas respostas da questão 22, nota-se que muitos estudantes reclamaram justamente do mercado de trabalho, muito competitivo e opressor. E para as mulheres, se mostra-se um ambiente repleto de assédio. Através das respostas dos alunos, pode-se concluir que as mulheres se sentem mais desvalorizadas que os homens estudando computação. Além disso, existe uma grande disparidade em relação à preocupação com as opiniões de outras pessoas sobre o desempenho baseado no gênero. Para amenizar estes problemas instituições de nível superior precisam adotar medidas que atenuem nos problemas relatados pelos alunos. Este trabalho contribui para o direcionamento de políticas educacionais, chamando a atenção para os possíveis problemas que mais contribuem para a evasão de mulheres dos cursos superiores de computação no cenário brasileiro, por meio de um mapeamento de diversos problemas encontrados em outros países. 
IX Congresso Brasileiro de Informática na Educação (CBIE 2020)

Anais do XXXI Simpósio Brasileiro de Informática na Educação (SBIE 2020)

\section{Referências}

Casad, B. J., Petzel, Z. W., and Ingalls, E. A. (2019). A model of threatening academic environments predicts women stem majors' self-esteem and engagement in stem. Sex Roles, 80(7-8):469-488.

Ceci, S. J. (2015). Women in the academy: Past, present, and future. Past as Prologue, 18(25):273.

Cheryan, S., Lombard, E. J., Hudson, L., Louis, K., Plaut, V. C., and Murphy, M. C. (2019). Double isolation: Identity expression threat predicts greater gender disparities in computer science. Self and Identity, pages 1-23.

Cheryan, S., Plaut, V. C., Davies, P. G., and Steele, C. M. (2009). Ambient belonging: how stereotypical cues impact gender participation in computer science. Journal of personality and social psychology, 97(6):1045.

DTI-MEC (2018). Rede federal de educação profissional, científica e tecnológica. http://plataformanilopecanha.mec.gov.br/2019.html. Mai 19, 2020.

Giannakos, M. N., Pappas, I. O., Jaccheri, L., and Sampson, D. G. (2017). Understanding student retention in computer science education: The role of environment, gains, barriers and usefulness. Education and Information Technologies, 22(5):2365-2382.

Leslie, S.-J., Cimpian, A., Meyer, M., and Freeland, E. (2015). Expectations of brilliance underlie gender distributions across academic disciplines. Science, 347(6219):262265.

Master, A., Cheryan, S., and Meltzoff, A. N. (2016). Computing whether she belongs: Stereotypes undermine girls' interest and sense of belonging in computer science. Journal of Educational Psychology, 108(3):424.

Michell, D., Szorenyi, A., Falkner, K., and Szabo, C. (2017). Broadening participation not border protection: how universities can support women in computer science. Journal of Higher Education Policy and Management, 39(4):406-422.

Misa, T. J. (2011). Gender codes: Why women are leaving computing. John Wiley \& Sons.

Mishkin, A. (2019). Applying self-determination theory towards motivating young women in computer science. In Proceedings of the 50th ACM Technical Symposium on Computer Science Education, pages 1025-1031.

Moss-Racusin, C. A., Sanzari, C., Caluori, N., and Rabasco, H. (2018). Gender bias produces gender gaps in stem engagement. Sex Roles, 79(11-12):651-670.

Santos, C. M. (2018). Por que as mulheres "desapareceram" dos cursos de computação? https://jornal.usp.br/universidade/por-que-as-mulheres-desapareceramdos-cursos-de-computacao/. Mai 19, 2020.

Strayhorn, T. L. (2018). College students' sense of belonging: A key to educational success for all students. Routledge.

Yin, R. K. (2015). Estudo de Caso-: Planejamento e métodos. Bookman editora. 